\title{
Avanços e desafios da participação institucionalizada no sistema de saúde do Brasil
}

Advances and Challenges of Institutionalized Participation in Brazil's Health System

Avancées et challenges de la participation institutionnalisée dans le cadre du système de santé du Brésil

José Patrício Bispo Júnior

\section{OpenEdition}

\section{Journals}

Edição electrónica

URL: http://journals.openedition.org/rccs/8269

DOI: $10.4000 /$ rccs. 8269

ISSN: 2182-7435

\section{Editora}

Centro de Estudos Sociais da Universidade de Coimbra

Edição impressa

Data de publição: 1 Dezembro 2018

Paginação: 99-122

ISSN: 0254-1106

\section{Refêrencia eletrónica}

José Patrício Bispo Júnior, «Avanços e desafios da participação institucionalizada no sistema de saúde do Brasil », Revista Crítica de Ciências Sociais [Online], 117 | 2018, colocado online no dia 03 dezembro 2018, criado a 19 abril 2019. URL : http://journals.openedition.org/rccs/8269 ; DOI $10.4000 /$ rccs. 8269

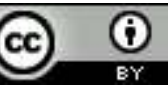




\section{JOSÉ PATRÍCIO BISPO jÚNIOR}

\section{Avanços e desafios da participação institucionalizada no sistema de saúde do Brasil}

O presente artigo tem como objetivo analisar os principais desafios e características da participação institucionalizada no sistema de saúde brasileiro. Discute, primeiramente, as características e os princípios do Sistema Único de Saúde, com destaque para a importância da mobilização social na conformação do atual sistema de saúde do país. Em seguida, apresentam-se as características e atribuições dos conselhos e conferências de saúde enquanto mecanismos institucionalizados de participação. Os conselhos de saúde são analisados quanto às características de composição paritária e função deliberativa. Por fim, discutem-se os resultados do estudo de caso do Conselho de Saúde do estado da Bahia. Evidencia-se o baixo poder de agenda dos representantes sociais e a frágil capacidade de influência do conselho na definição da política de saúde.

Palavras-chave: Brasil; democracia; participação cidadã; sistemas de saúde.

\section{Introdução}

Nas últimas décadas, reformas participativas ocuparam a agenda governamental em vários países. As pressões da sociedade civil por maior poder de influência e maior espaço nos processos de definição e acompanhamento das políticas públicas influenciaram o desenvolvimento de mecanismos institucionais de vocalização das demandas dos segmentos sociais. No Brasil, as reformas participativas conseguiram prover a abertura de órgãos e entidades estatais aos movimentos e às diversas formas de representação da sociedade. Nesse sentido, o país torna-se exemplo para as demais nações, por possibilitar a disseminação da participação da sociedade nas mais variadas áreas de políticas públicas, em todos os níveis de gestão e nos diversos momentos do ciclo da política - planejamento, gestão, execução e avaliação das políticas (Côrtes, 2009).

O incremento da participação social tem a premissa de tornar os governos mais democráticos e sensíveis às aspirações da população. Nos regimes liberais existem distorções sobre a identificação das preferências da sociedade, 
uma vez que os mecanismos de ausculta às demandas são débeis. As preferências são identificadas a partir dos resultados das eleições, que indicariam as opções ideológicas da maioria votante.

De acordo com a concepção minimalista de democracia, esta deve ser entendida como procedimento e como forma. Constitui-se em princípios gerais e regulamentos que tornem o convívio possível. Schumpeter (1976) enfatiza que a democracia é um método político e deve ser compreendida como arranjo institucional para se alcançar decisões políticas. Nesse sentido, a democracia é entendida enquanto atividade meio, ou seja, é utilizada apenas como mecanismo para se tomar decisões. Tal perspectiva reducionista não contempla outras dimensões inerentes aos regimes democráticos, como a garantia de direitos sociais. Bobbio (2009) caracteriza o regime democrático como um conjunto de regras e procedimentos para a formação de decisões coletivas, em que está prevista e facilitada a participação dos interessados. Além disso, inclui no conceito geral de democracia a estratégia de compromisso entre as partes para o respeito às decisões. Habermas (2002), ao discutir os modelos normativos de democracia, considera que o modelo liberal utiliza o regime democrático como estratégia de aglutinação e identificação de interesses.

Frente a esse contexto, o sufrágio universal constituiu-se como sinônimo de democracia e distribuição de poder. A possibilidade de estender o direito de escolha à massa trabalhadora confere o status democrático aos regimes liberais. A eleição é utilizada como procedimento e instrumento da sociedade para escolha dos representantes e das políticas. Por meio do voto, a população tem a chance de eleger entre as opções ideológicas e de políticas públicas a que melhor se adequa às suas expectativas.

No entanto, como chamam a atenção Lavalle et al. (2006), há sérias controvérsias e ressalvas quanto à capacidade de as eleições levarem à formação de governos realmente representativos das demandas dos cidadãos. As eleições democráticas e representativas distam de ser sinônimo de indicação de preferências sobre políticas públicas, isso, sobretudo, pela natural incapacidade de configuração desse processo. Os resultados dos processos eleitorais podem até registrar o bruto da opinião pública, mas não revelam envergadura para representar a vontade popular e o desejo coletivo (Dryzec, 2004).

A partir da segunda metade do século xx, as relações entre Estado e sociedade mudaram profundamente e a dinâmica social impôs novos comportamentos e posturas aos atores individuais e coletivos. Nessa conjuntura, as correlações de força se alteraram e a democracia representativa passou a ser questionada enquanto método capaz de responder às demandas materiais, culturais e participativas da sociedade. 
Assim, foram desenvolvidas várias iniciativas de promoção da participação social. Movimentos e fóruns participativos foram criados com o propósito de ampliar a democracia para além do processo eleitoral. Importante também frisar o processo de fragilização dos sindicatos como entidades tradicionais de representação de interesses da classe trabalhadora e outros segmentos sociais (Braga, 2014; Requena Mora e Rodríguez Victoriano, 2017).

Como consequência, as relações e os limites entre Estado e sociedade civil foram significativamente alteradas. Tanto as categorias Estado quanto sociedade civil, em seu significado atual, apresentam-se de forma emaranhada e com limite poroso e pouco definido (Borón, 2003).

Espaços de participação social e mecanismos de democratização do processo decisório são exemplos de aproximação e indefinição dos limites da relação entre Estado e sociedade civil. Para Santos e Avritzer (2005), a democracia é uma gramática de organização da sociedade e da relação entre o Estado e a sociedade. Questões sobre os papéis e limites da ação do Estado e da sociedade civil permeiam constantemente o debate sobre os mecanismos de democratização e participação.

Côrtes (2009) enfatiza os limites do conceito de sociedade civil para análise das relações entre Estado e sociedade. Destaca tanto a necessidade de desmistificação da positividade atribuída ao conceito de sociedade civil, vista como portadora de interesses gerais, quanto à negatividade conferida às instituições políticas, que tendem a agir de acordo com interesses corporativos e particulares. Tanto atores estatais como societais refletem e realizam escolhas movidas por interesses das instituições que representam, bem como por ideias e crenças compartilhadas por eles. Os atores agem, também, constrangidos e estimulados pelas instituições e pelas relações e redes sociais que construíram ao longo de suas trajetórias políticas. Desta forma, os fóruns participativos podem moldar a postura dos atores e, por constrangimento, induzir posicionamentos não esperados para o tipo de entidade que representam.

Santos e Avritzer (2005) destacam a peculiaridade do Brasil no que diz respeito ao papel da participação na construção da democracia, após um período de duas ditaduras no século Xx. As ações dos movimentos sociais, alicerçada na capacidade de aglutinar pessoas e propor mudanças, demandaram novas práticas políticas que acabaram por gerar novas formas de participação consagradas na Constituição de 1988. Nesse sentido, a constituição cidadã estabeleceu 14 princípios participativos na organização do Estado brasileiro e o mais importante desses é a participação da sociedade civil na deliberação sobre as políticas públicas (Avritzer, 2009). Assim, a participação institucionalizada é entendida nesse texto como a criação 
de conselhos e conferências de políticas públicas enquanto mecanismos oficiais e integrantes das estruturas dos órgãos do governo.

Dentre essas experiências participativas, a que foi desenvolvida no sistema de saúde ganhou notoriedade e destaque no cenário nacional e internacional (Paiva et al., 2014). Conforme será discutido adiante, a criação de conselhos e conferências de saúde representa um importante mecanismo de democratização do setor saúde, com a peculiaridade de se situarem na contramão da tradicional tendência clientelista e autoritária do Estado brasileiro (Gerschman, 2004).

Os conselhos possuem uma composição que privilegiam a participação comunitária. Assim, a população conquista um importante espaço para influenciar e definir os rumos das políticas de saúde e para acompanhar e fiscalizar as ações desenvolvidas. Com o processo de descentralização do sistema de saúde brasileiro e a criação de conselhos de saúde em todos os municípios e estados, a institucionalização da participação constitui-se no mais amplo fenômeno de democratização setorial e de compartilhamento de poder do Estado com a sociedade.

Ao tomar por referência os estudos de Dahl (2005), é possível sugerir que os conselhos de saúde, conforme instituído em seus marcos legais, apresentam características poliárquicas. Inclusividade e contestação pública são os dois fatores que caracterizam uma poliarquia. Assim, a depender da maior ou menor participação dos indivíduos - inclusividade - e da maior ou menor possibilidade de contestar as ações do governo e de interferir em suas decisões, os regimes se tornarão mais ou menos democráticos.

No caso dos conselhos de saúde, esses aglutinam a ampla possibilidade da contestação pública e da inclusividade. A inclusividade é materializada com a incorporação dos segmentos populares, a partir da representação dos usuários, bem como de outros segmentos a exemplo do empresariado e de profissionais de saúde. A contestação pública é concretizada com a possibilidade de o conselho propor e decidir por políticas de saúde que podem não necessariamente coincidir com as ideias dos gestores. Também as atribuições de controle e fiscalização sobre a gestão, inclusive nos aspectos econômicos e financeiros, contribuem para o desenvolvimento da contestação pública.

Frente a esse contexto, o presente artigo tem como objetivo apresentar e discutir os principais desafios e características da participação institucionalizada no sistema de saúde brasileiro. Para tanto, o manuscrito está organizado em três outras sessões. No tópico seguinte são apresentados um breve histórico, a lógica organizativa e os princípios do Sistema Único de Saúde (SUS). Em seguida, são analisadas as características e atribuições dos conselhos e conferências de saúde, como mecanismos 
institucionalizados de participação. Na sessão posterior são analisados os resultados do estudo de caso do Conselho de Saúde do estado da Bahia, com especial interesse no que toca ao poder de interferência dos representantes sociais e à capacidade do conselho em interferir sobre os rumos da política de saúde no estado da Bahia.

\section{O sistema de saúde do Brasil: breve histórico, princípios e características}

O sistema de saúde brasileiro, denominado Sistema Único de Saúde (SUS), foi criado na Assembleia Nacional Constituinte de 1988. O principal destaque do texto constitucional foi estabelecer a Saúde enquanto direito de todos e dever do Estado. Com o SUS, é instituído no Brasil o primeiro sistema nacional de saúde.

Anteriormente à criação do mesmo, existia no país um sistema de saúde vinculado ao sistema previdenciário, ao qual apenas os trabalhadores do setor formal tinham acesso. Em decorrência das grandes desigualdades existentes no país e das elevadas taxas de desemprego, havia grandes parcelas da população que não tinham acesso regular aos cuidados de saúde. A atuação do Estado estruturava-se através de campanhas sanitárias e programas específicos para o combate às endemias e epidemias de doenças infecciosas e parasitárias (Escorel, 2012). Conforme destacam Paim et al. (2011), o sistema de saúde do país era fragmentado, desigual e excludente, com diferentes serviços e níveis de cobertura.

Importante destacar que o SUS é a principal conquista do Movimento da Reforma Sanitária Brasileira. A reestruturação do sistema de saúde seguiu na contramão das reformas difundidas pelas agências internacionais e demais países, que questionavam a abrangência da proteção social por parte do Estado (Paim et al., 2011). A reforma sanitária brasileira desenvolveu-se no decorrer da década de 1980 em paralelo com a luta pelo fim do regime autoritário e pela transformação da realidade social e política do país. Neste contexto, um amplo movimento social de cunho democrático-popular cresceu no país que envolvia profissionais de saúde, acadêmicos, sindicatos, políticos e movimentos sociais (ibidem). Assim, pode-se afirmar que o sistema de saúde brasileiro é o resultado de um intenso processo de participação social, que à época logrou forte poder de influência na agenda política do país.

Em 1986, realizou-se a 8. ${ }^{a}$ Conferência Nacional de Saúde (CNS), marco do movimento da reforma sanitária. Conforme discutido adiante, esta foi a primeira conferência nacional que envolveu amplamente a sociedade civil e os movimentos sociais na discussão dos rumos do sistema de saúde. Com vasta participação popular, os debates fundamentaram-se em três temas: saúde como direito de cidadania; reformulação do sistema nacional de saúde; 
e financiamento do setor (Noronha et al., 2012). Também foram discutidas a concepção de saúde para além dos aspectos biológicos e a necessidade de criação de instâncias de participação social no âmbito do sistema de saúde (Escorel, 2012). O relatório da 8. ${ }^{a} \mathrm{CNS}$ constituiu-se em referência para todo o movimento sanitário e em alicerce para a construção do SUS (Escorel, 2012; Paim et al., 2011).

Após a realização da $8{ }^{a}$ conferência, o movimento sanitário ganhou ainda mais força e seguiu no processo de mobilização e defesa do ideário reformista. Nos anos seguintes (1987-1988), durante a Assembleia Nacional Constituinte, o movimento sanitário manifestou grande poder de influência ao garantir que o texto da saúde da Constituição Federal fosse elaborado com base nesse relatório, mesmo diante da forte oposição do setor privado e da federação brasileira de hospitais. Assim, a Constituição de 1988 estabeleceu que a saúde é parte da seguridade social e que o SUS constituiu-se em sistema universal, fundamentado no conceito ampliado de saúde.

Em 1990 foi publicada a Lei n. ${ }^{\circ} 8080$ de 19 de setembro, ${ }^{1}$ que regulamenta o SUS e estabelece os princípios e diretrizes do sistema. Dentre os 13 princípios e diretrizes estabelecidos, vale destacar: a universalidade do acesso aos serviços de saúde; a integralidade da assistência; a igualdade da assistência à saúde; a descentralização político-administrativa; a participação da comunidade.

Os princípios da universalidade do acesso, da integralidade da assistência e da igualdade conformam o SUS como um sistema nacional de saúde que garante a todos os brasileiros uma assistência integral conforme as suas necessidades. O acesso à saúde no país é um direito de cidadania, portanto não existem seguros públicos ou qualquer tipo de taxa ou copagamento para uso dos serviços no âmbito do SUS. Mesmo diante de problemas relacionados às dificuldades de acesso, demora no atendimento e qualidade de alguns serviços (Vargas et al., 2015), o SUS é considerado uma das maiores experiências de sistemas de saúde que se conhece (Paim et al., 2011) e uma política social de grande impacto sobre as iniquidades em saúde (Macinko e Harris, 2015).

A diretriz da descentralização político-administrativa orientou uma nova lógica organizava do sistema de saúde. A descentralização redefiniu as responsabilidades entre os entes da federação, proporcionando maior protagonismo e responsabilidades aos estados e, sobretudo, aos municípios. Com isso, cada município passou a ser responsável pela garantia da atenção à saúde dos cidadãos residentes e pela organização dos serviços de saúde

${ }_{{ }^{1} \text { Lei n. }}^{\circ}$ 8080/1990 de 19 de setembro. Diário Oficial da União (DOU), Seção 1, página 18055, Brasilia. 
em seu território. A descentralização está associada também à constituição de uma rede regionalizada e hierarquizada de serviços de saúde. Assim, os serviços, especialmente os de maior densidade tecnológica, não disponíveis em um determinado município, devem ser assegurados ao cidadão em outro território.

A participação da comunidade visa garantir que a população possa participar do processo de formulação de diretrizes e prioridades das políticas de saúde, da fiscalização do cumprimento dos dispositivos legais e normativos dos SUS e do controle e avaliação de ações e serviços de saúde executados nas três esferas de governo (Noronha et al., 2012). O envolvimento comunitário é um dos principais pilares do movimento sanitário e a criação do SUS é, em grande medida, resultado do intenso processo de mobilização da sociedade brasileira. O ideário sanitário tinha como propósito ir muito além da expansão do direito e da reforma setorial, compreendia a saúde como estratégia de democratização social e como potente elemento transformador de toda a sociedade (Lobato, 2009).

Nesse sentido, o movimento sanitário fez valer que a participação social fosse institucionalizada no âmbito do Sistema de Saúde. Conforme destaca Lobato (2009), este movimento buscou a criação de um aparato legal a partir da inclusão de um conjunto de mecanismos inovadores que garantissem formalmente a participação dos cidadãos na estrutura administrativa do SUS, como ferramenta para consolidação de Estado democrático e sustentação do próprio movimento da reforma sanitária.

\section{Mecanismos institucionais de participação no SUS: as conferências e os conselhos de saúde}

Ainda como parte do processo de regulamentação do SUS, em 1990 foi também publicada a Lei n. ${ }^{\circ} 8142$ de 28 de dezembro, ${ }^{2}$ que dispõe sobre a participação da comunidade na gestão do sistema de saúde. Essa lei institucionaliza e regulamenta os espaços participativos no âmbito do SUS. Estabelece que as instâncias de participação são as conferências de saúde e os conselhos de saúde e que ambas devem estar presentes em todas as unidades da federação.

Segundo Noronha et al. (2012), a institucionalização da participação no SUS é coerente com três ideias principais: 1) o ideal da democracia participativa, que envolve o controle da sociedade sobre o poder público e as políticas de saúde; 2 ) o desenvolvimento de uma gestão participativa, em que o processo de formulação e de implementação da política de saúde

${ }^{2}$ Lei 8142/1990 de 28 de dezembro. DOU, Seção 1, página 25694, Brasília. 
pelos gestores devem ser compartilhados pela sociedade; 3 ) a necessidade de propiciar um ciclo virtuoso entre a sociedade organizada e as instituições públicas de saúde, que rompam com padrões de comportamento clientelista e patrimonialista ainda presentes na sociedade brasileira.

\subsection{Conferências de saúde no Brasil}

Embora tenham sido estabelecidas a partir de 1990 como mecanismos integrantes da estrutura organizativa do SUS, as conferências de saúde têm uma longa história no Brasil e o seu surgimento antecede em muito a criação do atual sistema de saúde. A primeira conferência nacional de saúde foi realizada em 1941 e até à presente data já foram realizadas no país 15 conferências (Quadro 1).

QUADRO 1 - Conferências nacionais de saúde do Brasil, ano de realização e temas

\begin{tabular}{|c|c|c|}
\hline Conferência & Ano & Temas \\
\hline 1. ${ }^{a}$ CNS & 1941 & $\begin{array}{l}\text { 1. Organização sanitária estadual e municipal } \\
\text { 2. Ampliação e sistematização das campanhas nacionais contra } \\
\text { a hanseníase e a tuberculose } \\
\text { 3. Determinação das medidas para desenvolvimento dos serviços } \\
\text { básicos de saneamento } \\
\text { 4. Plano de desenvolvimento da obra nacional de proteção } \\
\text { à maternidade, infância e adolescência }\end{array}$ \\
\hline $2 .^{a} \mathrm{CNS}$ & 1950 & Legislação referente à higiene e à segurança no trabalho \\
\hline 3. ${ }^{\mathrm{a}} \mathrm{CNS}$ & 1963 & $\begin{array}{l}\text { 1. Situação sanitária da população brasileira } \\
\text { 2. Distribuição e coordenação das atividades médico-sanitárias } \\
\text { nos níveis federal, estadual e municipal } \\
\text { 3. Municipalização dos serviços de saúde } \\
\text { 4. Fixação de um plano nacional de saúde }\end{array}$ \\
\hline $4 .^{\mathrm{a}} \mathrm{CNS}$ & 1967 & Recursos humanos para as atividades em saúde \\
\hline $5 .^{a} \mathrm{CNS}$ & 1975 & $\begin{array}{l}\text { 1. Implementação do Sistema Nacional de Saúde } \\
\text { 2. Programa de Saúde Materno-Infantil } \\
\text { 3. Sistema Nacional de Vigilância Epidemiológica } \\
\text { 4. Programa de Controle das Grandes Endemias } \\
\text { 5. Programa de Extensão das Ações de Saúde às Populações Rurais }\end{array}$ \\
\hline 6. ${ }^{\mathrm{a}} \mathrm{CNS}$ & 1977 & $\begin{array}{l}\text { 1. Situação atual do controle das grandes endemias } \\
\text { 2. Operacionalização dos novos diplomas legais básicos aprovados } \\
\text { pelo governo federal em matéria de saúde } \\
\text { 3. Interiorização dos serviços de saúde } \\
\text { 4. Política Nacional de Saúde }\end{array}$ \\
\hline 7. ${ }^{\mathrm{a}} \mathrm{CNS}$ & 1980 & Extensão das ações de saúde por meio dos serviços básicos. \\
\hline
\end{tabular}


cont.

\begin{tabular}{|c|c|c|}
\hline Conferência & Ano & Temas \\
\hline 8. ${ }^{a} \mathrm{CNS}$ & 1986 & $\begin{array}{l}\text { 1. Saúde como direito } \\
\text { 2. Reformulação do Sistema Nacional de Saúde } \\
\text { 3. Financiamento setorial }\end{array}$ \\
\hline 9. ${ }^{\mathrm{a}} \mathrm{CNS}$ & 1992 & Municipalização é o caminho \\
\hline $10 .^{a} \mathrm{CNS}$ & 1996 & $\begin{array}{l}\text { 1. Saúde, cidadania e políticas públicas } \\
\text { 2. Gestão e organização dos serviços de saúde } \\
\text { 3. Controle social na saúde } \\
\text { 4. Financiamento da saúde } \\
\text { 5. Recursos humanos para a saúde } \\
\text { 6. Atenção integral à saúde }\end{array}$ \\
\hline $11 .^{a} \mathrm{CNS}$ & 2000 & $\begin{array}{l}\text { Efetivando o SUS - Acesso, qualidade e humanização na atenção } \\
\text { à saúde com controle social }\end{array}$ \\
\hline $12 .^{a} \mathrm{CNS}$ & 2003 & $\begin{array}{l}\text { Saúde - Direito de todos e dever do Estado, o SUS que temos } \\
\text { e o SUS que queremos }\end{array}$ \\
\hline $13 .^{a} \mathrm{CNS}$ & 2007 & Saúde e qualidade de vida, políticas de Estado e desenvolvimento \\
\hline $14 .^{a}$ CNS & 2011 & $\begin{array}{l}\text { Todos usam o SUS! SUS na seguridade social - Política pública, } \\
\text { patrimônio do povo brasileiro }\end{array}$ \\
\hline $15 .^{a}$ CNS & 2015 & $\begin{array}{l}\text { Saúde pública de qualidade para cuidar bem das pessoas: } \\
\text { direito do povo brasileiro }\end{array}$ \\
\hline
\end{tabular}

Fonte: Elaborado pelo autor a partir de Brasil (2014), CONASS (2009) e Faria e Lins (2013).

O propósito, formato e relevo político das conferências nacionais variaram muito ao longo dos anos. É possível classificar a trajetória das conferências em dois tempos históricos, destacando-se como marco a 8. ${ }^{a} \mathrm{CNS}$, realizada em 1986. As conferências foram instituídas pela Lei n. ${ }^{\circ} 378$ de 1937 como espaço de discussão e avaliação da situação de saúde, no entanto eram restritas a especialistas e burocratas do nível federal e dos governos estaduais. Constituíam espaços estritamente intergovernamentais e de caráter técnico, dos quais participavam apenas as autoridades e os representantes dos governos (CONASS, 2009).

Outra característica das primeiras conferências foi a irregularidade temporal da sua realização, previstas a cada dois anos (ibidem). Embora a lei que institui as conferências seja de 1937, a primeira CNS só aconteceu em 1941. Da primeira até à segunda conferência transcorreram nove anos e a terceira só foi realizada 13 anos após a segunda (Quadro 1). O que significa que em nenhum período foi obedecido o intervalo de tempo de dois anos entre as conferências.

A 8. ${ }^{a} \mathrm{CNS}$ representou um ponto de inflexão na história das conferências de saúde. Essa conferência contou com grande participação popular, 
inaugurando um novo formato e conceito das conferências no país. A partir de então, as conferências deixaram de ser um espaço exclusivamente técnico e passaram também a constituir um canal de escuta de setores populares e de diversas representações da sociedade, bem como de amplo debate sobre os rumos do sistema de saúde.

A Lei n. ${ }^{\circ} 8142 / 1990$ estabeleceu critérios e fundamentos para a realização das conferências na era SUS. Segundo ela, estas devem ocorrer a cada quatro anos em todas as esferas de governo. A forma organizativa adotada é a convocação da conferência nacional pelo Ministério da Saúde ou pelo Conselho Nacional de Saúde. Como etapas que antecedem a conferência nacional são realizadas as conferências estaduais e as conferências municipais.

As conferências envolvem a representação de diversos segmentos sociais, a exemplo de: representações comunitárias e populares; trabalhadores da saúde; sindicatos; gestores; acadêmicos e prestadores privados de serviços. A composição dos delegados de cada conferência obedece ao princípio da paridade, pelo que metade dos membros da conferência consiste em representantes sociais, denominados de usuários, e a outra metade é dividida entre trabalhadores de saúde (25\%) e gestores e prestadores de saúde, formando um bloco com $25 \%$ dos delegados.

Os objetivos das conferências consistem em avaliar a situação de saúde e propor diretrizes para formulação da política de saúde. Desta forma, as conferências de saúde devem servir como ferramenta de planejamento do SUS e balizar o processo de tomada de decisão em todas as esferas de governo.

Mesmo diante da importância da inclusão participativa no setor sanitário, estudos demonstram a existência de fragilidades e desafios no que se refere às conferências de saúde (Müller Neto e Artmann, 2014; Ricardi et al., 2017). Em estudo realizado por Ricardi et al. (2017) com o propósito de analisar o modo como as conferências nacionais têm pautado o processo de planejamento do Ministério da Saúde, observou-se que em âmbito nacional o processo de planejamento pouco considera o que foi discutido nas conferências. Um dos aspectos limitantes do efetivo papel das CNS foi a questão da temporalidade. Nas situações analisadas, a realização das conferências ocorre em período posterior à elaboração do Plano Nacional de Saúde, que tem a duração de quatro anos. Outra fragilidade identificada foi a escassez de mecanismos de monitoramento e avaliação. Após a publicação do relatório da conferência não há mecanismos que efetuem o acompanhamento e verifiquem se as diretrizes definidas são incorporadas.

Por sua vez, Avritzer (2013), ao analisar a importância das conferências no modo de fazer política do governo federal, identifica que a expansão das conferências nacionais em diversas áreas impactou sobre o poder legislativo 
e impulsionou o Congresso Nacional a se debruçar sobre novos arranjos para as políticas sociais. Ainda segundo o autor, as conferências nacionais têm um importante impacto nas políticas públicas destinadas aos grupos minoritários e na ampliação das formas deliberativas de tomadas de decisão.

Diante desse cenário, vale refletir que as conferências nacionais de saúde, antecedidas pelas etapas municipais e estaduais, são grandes eventos cívicos que mobilizam atores sociais e institucionais em todo o país para o debate e proposições de aprimoramento do sistema nacional de saúde. Mesmo diante dos desafios inerentes à realização de eventos de grande porte e da diversidade dos interesses na área da saúde, as conferências de saúde no Brasil são espaços de ampliação democrática, de inclusão participativa e de ausculta das demandas sociais em saúde.

\subsection{Conselhos de saúde no Brasil}

Os conselhos de saúde são colegiados de caráter permanente e também existentes nos três níveis de governo. Todos os estados e municípios possuem obrigatoriamente um conselho de saúde, para além do Conselho Nacional de Saúde. Essas instâncias participativas fazem parte da estrutura organizacional e administrativa do setor. É estabelecido que a esfera de governo correspondente garante autonomia administrativa e financeira ao conselho para o desenvolvimento das suas atividades.

Os aspectos relacionados à composição e atribuições dos conselhos concedem a esses fóruns um arranjo participativo bastante avançado no que diz respeito ao poder de influência da sociedade civil sobre as políticas de saúde. No que tange à composição, a Resolução n. ${ }^{\circ}$ 453/2012 do Conselho Nacional de Saúde 3 estabelece que os conselhos devem ser formados por quatro grupos de participantes: usuários, trabalhadores em saúde, prestadores de serviços públicos e privados e gestores governamentais em saúde. Nos conselhos também é observado o princípio da paridade, segundo o qual a representação dos usuários deve equivaler a $50 \%$ dos membros. A representação dos trabalhadores em saúde equivale a $25 \%$, sendo os outros $25 \%$ distribuídos entre gestores e prestadores de serviços. Essa arquitetura organizacional constitui-se num importante fator de fortalecimento da democracia, pois insere no cenário sanitário atores pertencentes a segmentos sociais de diversas matizes ideológicas e políticas (Bispo Júnior e Gerschman, 2013).

Não obstante a importante abrangência de representações no conselho, um dos problemas desse arranjo organizacional é a dificuldade de definição sobre as representações dos usuários. Nesse sentido, duas questões

${ }^{3}$ Resolução n. ${ }^{\circ}$ 453, de 10 de maio de 2012. DOU, Conselho Nacional de Saúde, Brasília. 
apresentam-se como fundamentais nesse debate. Quem são os(a) usuários do SUS? Como escolher os representantes desse segmento?

Como o SUS é um sistema universal de livre acesso aos cidadãos brasileiros, a resposta à primeira questão é que todos(a) são usuários(s) do SUS, inclusive os segmentos que na composição do conselho têm assento diferenciado, como os trabalhadores da saúde, os gestores e os prestadores. Tal situação tem gerado problemas em determinadas localidades no que se refere a que instâncias devem assumir as cadeiras destinadas aos usuários. Em algumas situações, entre os representantes dos usuários observam-se alguns que são provenientes do setor privado (Pereira et al., 2009), de deputados (Escorel e Delgado, 2008) e de vereadores (Bispo Júnior e Sampaio, 2008).

Côrtes (2009) reflete que o conceito de usuário de serviços, assim como o de consumidor, é inadequado para analisar as relações sociais que se desenvolvem nos fóruns participativos. Segundo a autora, tais noções são derivadas do campo da economia e referem-se especificamente a indivíduos que usam determinados bens e serviços oferecidos por diferentes vendedores e prestadores. $\mathrm{O}$ conceito pode ser útil para análises gerenciais e administrativas da qualidade e condições da oferta dos serviços prestados. Todavia verifica-se que não é a denominação mais apropriada e tampouco o instrumento analítico adequado para compreensão de processos políticos complexos e que envolvam a relação entre Estado e sociedade.

No que tange às atribuições, a Resolução n. ${ }^{\circ}$ 453/2012 do Conselho Nacional de Saúde estabelece que os conselhos têm a função deliberativa e que as resoluções do mesmo serão obrigatoriamente homologadas pelo chefe do poder legalmente constituído no prazo máximo de 30 dias. Dentre as competências, cabe ainda aos conselhos de saúde atuar na formulação e no controle da execução da política de saúde, inclusive nos aspectos econômicos e financeiros. Tais prerrogativas sugerem um forte mecanismo de compartilhamento de poder dos governos com a sociedade civil.

No entanto, esse é um processo social e político complexo e cheio de controvérsias. Na literatura especializada observa-se um importante debate sobre o que se constituiria no caráter deliberativo do conselho. De acordo com Serapioni (2014), na literatura sociológica e política predominam duas visões sobre o termo deliberativo. Na visão anglo-saxônica, deliberar expressa a possibilidade de um grupo debater e analisar determinadas questões, algo que não está obrigatoriamente relacionado ao processo de tomada de decisão. Na literatura do Brasil, a função deliberativa dos conselhos está mais relacionada ao poder de tomar decisões na área da saúde, mesmo que contrariem interesses e proposições dos representantes dos gestores. 
Dessa forma, evidencia-se um debate dicotômico sobre o sentido da deliberação: como prática do debate esclarecido sem estar, no entanto, vinculado ao processo decisório ou como processo efetivo de tomada de decisão, após a discussão esclarecida. Serapioni (2014) destaca a importância dos resultados do processo participativo. Embora participar tenha uma função em si mesma, as instâncias participativas devem ter a capacidade de exercer influência sobre as políticas, sobre pena de gerar descrédito e de desmobilização para os que participam. Para Cohen (2009), a noção de democracia deliberativa está enraizada num ideal de compromisso com a resolução de problemas a partir da escolha coletiva. Cidadãos em tal ordem entendem as instituições deliberativas como legítimas e esperam a continuidade de ações após a deliberação pública livre. Segundo Abelson et al. (2003), a deliberação vai muito além da simples discussão de algo; está implicada com o resultado dessa mesma discussão e a efetivação das decisões tomadas.

Especificamente sobre os conselhos de saúde, o atributo deliberativo os diferencia dos demais conselhos de outros segmentos sociais, bem como instâncias de diversos países com natureza apenas consultiva na participação em saúde (Bispo Júnior e Gerschman, 2013). Foram desenvolvidos no país normas operacionais e marcos organizativos com o intuito de garantir o pleno funcionamento dos conselhos. Todas as ações e políticas de saúde devem ser obrigatoriamente aprovadas nos conselhos de saúde, sob pena de não receberem repasse de recursos federais para o financiamento do setor. Desta forma, os gestores devem submeter e obter a aprovação do conselho para as políticas a serem desenvolvidas.

Tal processo deliberativo pressupõe compartilhamento de poder por parte dos gestores, que até então detinham o monopólio do poder decisório. Nesse contexto, é natural imaginar que essa prática política está sujeita a resistências. Estudos demonstram que em diversas localidades os gestores procuram obstaculizar ou manipular o funcionamento desses fóruns (Ventura et al., 2017; Bispo Júnior e Pinheiro, 2016; Oliveira e Pinheiro, 2010). Moreira (2016) afirma que os conselhos de saúde vivenciam um processo de deslegitimação da função deliberativa seja por via direta, com a não homologação das deliberações por parte dos gestores, seja por via indireta, com restrições às condições de funcionamento e práticas manipulativas dos gestores nos conselhos.

Conforme destaca Gerschman (2004), os conselhos de saúde são como convidados inconvenientes ao exercício do processo decisório e a sua postura firme e coesa é fundamental para o ganho de respeito e espaço na arena deliberativa. Segundo Labra (2009), o processo deliberativo é, por natureza, complexo e cheio de incertezas. As plenárias do conselho são espaços de 
estimado valor para ampliação da democracia e as resoluções são, tipicamente, produtos de processos decisórios. Todavia, não se pode desconsiderar que as deliberações dos conselhos são apenas parte de um processo muito maior, complexo, demorado e incerto. As resoluções dos conselhos não constituem um ciclo completo nem se pretendem finalísticas.

A decisão final não ocorre unicamente a partir da deliberação do conselho. A decisão e implementação de uma política é o resultado do embate de várias forças. Atores diversos buscam fazer valer suas intenções com articulação e mecanismos de pressão em diferentes arenas, a exemplo dos poderes legislativo e judiciário, das burocracias estatais, da mídia, ou até mesmo manipulando o imaginário popular (Labra, 2009). Assim, vale destacar que as dificuldades e resistências ao processo de incorporação de atores sociais nos espaços deliberativos não podem ser consideradas sinônimos de inópia ou da pouca importância dos conselhos de saúde.

\section{Entre a institucionalização e a efetiva participação: o caso do Conselho de Saúde do estado da Bahia \\ 3.1. Objetivo, método e cenário de estudo}

A fim de ilustrar a participação institucionalizada no sistema de saúde do Brasil, será explorado o estudo realizado no Conselho de Saúde do estado da Bahia (CES/BA) (Bispo Júnior, 2013). O objetivo da pesquisa foi analisar o conselho estadual de saúde enquanto espaço de construção coletiva das políticas de saúde, em dois períodos políticos com matrizes ideológicas distintas. O recorte temporal do estudo foi de 2003 a 2011. Esse período pode dividir-se em dois momentos: de 2003 a 2006, em que o estado era governado pelo então Partido da Frente Liberal (PFL), de orientação conservadora e privatizante; e entre 2007 e 2011, em que o governo foi conduzido pelo Partido dos Trabalhadores, em uma linha de centro-esquerda. Nesse artigo, se dará ênfase à análise sobre o poder de interferência dos representantes sociais no âmbito do conselho e a capacidade deste em interferir sobre os rumos da política de saúde no estado.

A presente investigação caracteriza-se como estudo de caso. Os dados e informações que subsidiaram o estudo foram obtidos por meio de entrevistas semiestruturadas, de observação participante da dinâmica do conselho e de análise documental. Foram entrevistados 20 conselheiros e ex-conselheiros de saúde, assim distribuídos conforme o segmento representado: sete usuários; quatro trabalhadores da área da saúde e nove gestores e prestadores públicos e privados. As entrevistas foram realizadas entre fevereiro e junho de 2012. Sobre os documentos, foram analisados as atas do plenário do conselho, resoluções do conselho, regimentos internos, relatórios de gestão, 
planos de saúde e documentos oficiais com leis e portarias da Secretaria de Saúde. Os documentos analisados correspondem ao período de realização do estudo, entre 2003 e 2011. Também foram observadas as reuniões plenárias do conselho no período de 12 meses, entre maio de 2011 e abril de 2012 e uma conferência estadual de saúde do estado, ocorrida entre 12 e 15 de setembro de 2011.

Os anos de existência do conselho da Bahia podem ser agrupados em dois períodos. Da sua implantação, em 1993, até 2006, o estado foi governado por um grupo político conservador, de tradição autoritária e de pouca sensibilidade em relação às questões sociais e participativas. Isso se constitui numa grande contradição no que se refere à instância decisória da saúde. No momento em que o SUS assume uma postura de democratização dos espaços de decisão, com a criação dos conselhos e conferências de saúde, assume o poder na Bahia um governo de orientação pouco participativa, que perdura por 16 anos. Todavia, em 2006, o grupo conservador perde a eleição estadual para o Partido dos Trabalhadores (PT). A partir de 2007, assume o governo do estado um grupo político que defende ideias de democratização da gestão e de envolvimento da população na condução das políticas públicas. Assim, buscou-se analisar o desempenho do conselho da Bahia e o poder de influência dos representantes sociais frente a esses dois cenários políticos.

O conselho estadual de saúde foi criado pela Lei Estadual n. ${ }^{\circ}$ 6074, de 22 de maio de $1991 .{ }^{4}$ A Lei n. ${ }^{\circ}$ 6074/91 dispõe sobre toda a estrutura administrativa do estado. Desta forma, a criação do CES/BA não ocorreu a partir de um ato administrativo próprio e direcionado à institucionalização da participação social no estado. O propósito da referida lei foi a reestruturação organizacional de toda administração pública do estado.

Embora o CES/BA tenha sido criado legalmente em 1991, a sua implementação e o respetivo funcionamento ocorreu apenas em 1993. A primeira reunião do conselho aconteceu em 21 de julho de 1993, com um intervalo superior a dois anos entre o ato de criação e a efetiva implementação. A lei de criação do conselho só foi alterada em 2011, com a publicação da Lei n. ${ }^{\circ}$ 12.053/2011, que dispõe sobre a nova estrutura do CES/BA. ${ }^{5}$

\footnotetext{
${ }^{4}$ Lei Estadual n. ${ }^{\circ}$ 6074/91, de 22 de maio de 1991 - Modifica a estrutura organizacional da Administração Pública Estadual e dá outras providências, Diário Oficial do Estado da Bahia, 23 de maio de 1991.

${ }^{5}$ Lei Estadual n. ${ }^{\circ}$ 12.053/2011, de 7 de janeiro de 2011 - Dispõe sobre a estrutura do Conselho de Saúde Estadual da Bahia e dá outras providências, Diário Oficial do Estado da Bahia, 8 de janeiro de 2011.
} 


\subsection{Composição do conselho}

De 2003 até 2012, o Conselho de Saúde do estado da Bahia manteve uma composição não condizente com perspectiva de participação paritária dos segmentos sociais e populares. O conselho era composto por 24 representantes, 12 dos quais em nome dos usuários. No entanto, a ocupação da representação dos usuários era feita de forma que pouco permitia valorizar a representação popular. Dos 12 assentos dos usuários, cinco eram de representantes de segmento de mercado, a exemplo da Federação da Indústria do Estado da Bahia (FIEB), e um era de representação dos deputados estaduais. Ou seja, apenas metade da representação dos usuários era de fato destinada aos representantes de segmentos sociais.

Já na gestão do Partido dos Trabalhadores, em 2012 o conselho da Bahia sofre uma importante reestruturação que modifica e amplia o espaço destinado à representação popular: passa a ser composto por $32 \mathrm{mem}$ bros, 23 dos quais representantes sociais. Os representantes de mercado, que na composição anterior possuíam $33 \%$ dos assentos, passaram a ocupar apenas $9 \%$ do total. Tal situação demonstra os avanços na representação de segmentos sociais no conselho.

\subsection{Poder de agenda dos representantes sociais}

De acordo com Silva et al. (2009), o controle sobre o processo de formação da agenda de discussão se constitui em um dos principais indicadores relativos à distribuição do poder entre os participantes de um espaço deliberativo. No conselho da Bahia, apesar da possibilidade regimental de inclusão de temas por parte de usuários e trabalhadores, o poder de agenda desses segmentos mostrou-se comprovadamente baixo. Embora representantes dos gestores em saúde afirmem que a pauta é definida democraticamente a partir da demanda dos conselheiros, verifica-se que a pauta era construída exclusivamente conforme conveniência da gestão.

Sobre os temas discutidos no âmbito do conselho, os referentes às políticas e programas de saúde e às prestações de contas e aprovação de relatórios foram os predominantes. Embora estas sejam duas temáticas de grande relevância para o exercício do controle social, é importante destacar que esses temas são pautados por direcionamento da gestão. A discussão de políticas e programas de saúde é motivada principalmente pela obrigatoriedade legal de aprovação no conselho das ações a serem implementadas pela secretaria de saúde. Muitas dessas políticas e programas são proposições do Ministério da Saúde que demandam homologação do conselho estadual, a fim de que o estado possa receber a transferência de recursos financeiros. 
Quando o tema entrava em pauta, a dinâmica adotada se constituía de uma apresentação técnica, seguida de uma breve discussão, contando com momentos para os conselheiros esclarecerem possíveis dúvidas, ocorrendo logo em seguida a votação para se aprovar a referida política ou o programa.

Esse modelo de condução foi questionado por muitos conselheiros, que argumentaram sobre o pouco tempo de debate destinado a conhecer a fundo a política ou o programa a ser implementado. Também é colocada em questão a lógica indutiva em favor da aprovação, visto que o debate era conduzido de uma forma que permitia a criação de mecanismos que constrangiam os representantes sociais a aprovar as propostas mesmo sem conhecer a contento o seu conteúdo, com o argumento de que a não aprovação poderia prejudicar a ampliação de serviços para a população. Nesse contexto, é possível concluir que os gestores mantêm rígido controle sobre a formação da pauta, o que sinaliza a existência de relações assimétricas de poder e a dificuldade visível por parte das entidades sociais vocalizarem as suas demandas.

$\mathrm{Na}$ comparação entre as duas gestões, evidencia-se um processo de avanço limitado no desenvolvimento da participação social. Durante a gestão do Partido dos Trabalhadores foi realizada a reestruturação do conselho com abertura e estímulo à maior participação dos movimentos sociais, o que evidencia a inciativa em direção à democratização do conselho. No entanto, o rigoroso controle da pauta e da agenda de discussão sinaliza a limitação na democratização da saúde em ambos os governos analisados.

Ao retomar os critérios propostos por Dahl (2005), de inclusividade e contestação pública como os parâmetros que possibilitam maior participação e permeabilidade ao processo decisório, é possível inferir que o conselho da Bahia avançou apenas parcialmente no sentido de uma maior democratização de suas atividades. No que tange a inclusividade, comprovou-se um crescente processo de ampliação desta, com a valorização da participação popular e o aumento do número de entidades sociais representadas no conselho. No entanto, a postura por parte dos gestores, no que toca a permanecerem resistentes à abertura do controle da agenda de discussão, limita sobremaneira a possibilidade de os setores populares influenciarem os rumos da política, conduzindo assim a um incompleto processo de democratização dessa instância participativa.

\subsection{Efetividade deliberativa e o poder de influência do Conselho de Saúde}

A análise do poder de interferência do conselho na definição e condução da política de saúde do estado foi embasada no conceito de efetividade 
deliberativa. Para Cunha (2007), a efetividade deliberativa está relacionada à capacidade efetiva de as instituições influenciarem, controlarem e decidirem sobre determinada política pública. Nesse sentido, a análise se pautou no poder do conselho em influenciar os rumos das políticas de saúde e em exercer controle e acompanhamento da execução.

No caso da Bahia, evidencia-se o diminuto poder de influência do conselho sobre a definição da política de saúde do estado. Apesar de manter um bom nível discursivo em suas reuniões plenárias, o conselho revela baixa capacidade propositiva sobre a política de saúde, caracterizando-se muito mais como espaço de homologação das proposições do gestor do que como locus de avaliação e direcionamento da política de saúde estadual. Observou-se um direcionamento para atividades de cunho burocrático, com predomínio de acompanhamento das prestações de contas e aprovação de relatórios de gestão. A atuação propositiva sobre políticas mostrou-se frágil.

Também foram detectadas fragilidades na capacidade de o conselho acompanhar o processo de implementação das políticas de saúde deliberadas. Foi relatado que a multiplicidade de atribuições e responsabilidades a cargo dos conselheiros constitui-se como fator limitador para o acompanhamento das deliberações proferidas. As ações do conselho são demasiadamente amplas, de modo que, para que fosse possível o conselheiro cumprir suas responsabilidades conforme preconizado, ele teria que se dedicar integralmente à função de conselheiro.

Por sua vez, Delgado e Escorel (2008) salientam que os marcos legais que regulamentam os conselhos de saúde têm sobrevalorizado a dimensão técnica, o que parece afastar a dimensão política inerente ao processo democrático. Assim, um desvio tecnocrático estaria balizando as competências normatizadas, extirpando dos conselhos a função política e participativa, com sobrecarga de atribuições fiscalizatórias nem sempre passíveis de serem desempenhadas pelos representantes.

Ainda sobre o acompanhamento das políticas, deve-se destacar que a implementação de uma política não é um processo simples e imediato. Em muitos casos, o conselho aprova ações que exigem articulação intersetorial e que demandam um longo período de tempo para serem efetivadas. Assim, o acompanhamento da ação é de difícil controle por sua própria natureza. Além do mais, a implementação efetiva não depende, muitas vezes, apenas das ações dos gestores em saúde. A concretização de uma deliberação do conselho pode estar sujeita às vontades de outros segmentos sociais e de governo, a exemplo das áreas econômica e de planejamento, nem sempre sensíveis às demandas sociais. 


\section{Conclusão}

As reflexões apresentadas no presente artigo apontam para a importância da institucionalização da participação social no sistema de saúde brasileiro. As conferências e os conselhos de saúde constituem-se em importantes mecanismos de inovação democrática, de fomento à participação e de inserção de segmentos sociais na arena deliberativa em saúde. Não obstante a importância de tais avanços, as instâncias participativas também enfrentam dificuldades para constituir-se enquanto mecanismos de vocalização das demandas sociais e em exercer efetiva influência sobre as políticas de saúde.

O caso do Conselho de Saúde do estado da Bahia ilustra os avanços e entraves para a democratização do setor, com persistências de relações assimétricas de poder e resistências por parte dos gestores em democratizar o processo decisório. $\mathrm{Na}$ análise empreendida, observaram-se diferenças consideráveis e também similaridades entre as duas gestões. Pode-se concluir que tais diferenças e similaridades guardam relação com os pressupostos de inclusividade e contestação pública. O estudo demonstrou que na gestão do Partido dos Trabalhadores muito se avançou na perspectiva da inclusividade, com incremento das representações dos segmentos sociais e diminuição dos espaços das representações de mercado. Por sua vez, quando se analisa a dimensão da contestação pública, relacionada com a capacidade do conselho em pautar temas e interferir nos rumos da política, conclui-se que ambas as gestões mantêm impermeável controle sobre a agenda e práticas pouco democráticas no processo de definição das políticas.

A democratização do setor da saúde perpassa não apenas pela manutenção da exigência legal de funcionamento dos conselhos de saúde, mas, também, pela disposição das autoridades em compartilhar poder e incorporar os anseios e aspirações dos representantes societais. Por fim, cabe refletir sobre a limitada capacidade de influência das representações dos segmentos sociais no âmbito do conselho. A qualidade da representação nas instâncias participativas é determinada pelo grau de comprometimento e participação da sociedade no processo de construção e implementação das políticas. Assim, a representatividade está sempre assegurada onde existe o interesse e a participação daqueles que serão afetados pela política, ao tempo que a representação tende a ser frágil em contextos de apatia participativa e isolamento do representante.

Revisto por Rita Cabral 


\section{Referências bibliográficas}

Abelson, Julia; Eyles, John; McLeod, Christopher B.; Collins, Patricia; McMullan, Colin; Forest, Pierre-Gerlier (2003), "Does Deliberation Make a Difference? Results from a Citizens Panel Study of Health Goals Priority Setting”, Health Policy, 66(1), 95-106. Avritzer, Leonardo (2009), "Associativismo e participação na saúde: uma análise da questão na região Nordeste”, in Sônia Fleury; Lenaura Lobato (orgs.), Participação, democracia e saúde. Rio de Janeiro: Cebes, 151-174.

Avritzer, Leonardo (2013), "Conferências nacionais: ampliando e redefinindo os padrões de participação social no Brasil”, in Leonardo Avritzer; Clóvis Souza (orgs.), Conferências nacionais: atores, dinâmicas participativas e efetividade. Brasília: IPEA - Instituto de Pesquisa Econômica Aplicada, 207-242.

Bispo Júnior, José Patrício (2013), "Participação social e relações de poder no Conselho Estadual de Saúde da Bahia". Tese de Doutorado em Ciências na área da Saúde Pública apresentada na Escola Nacional de Saúde Pública, Rio de Janeiro, Brasil.

Bispo Júnior, José Patrício; Gerschman, Sílvia (2013), "Potencial participativo e função deliberativa. Um debate sobre a ampliação da democracia por meio dos conselhos de saúde", Ciência \& Saúde Coletiva, 18(1), 7-16.

Bispo Júnior, José Patrício; Pinheiro, Gleide Magali Lemos (2016), "Participação social e relação de poder na definição das políticas de saúde no estado da Bahia", O público e o privado, 27, 17-37.

Bispo Júnior, José Patrício; Sampaio, José Jackson (2008), “Participação social em saúde em áreas rurais do Nordeste do Brasil”, Revista Panamericana de Salud Pública, 23(6), 403-409.

Bobbio, Noberto (2009), O futuro da democracia. São Paulo: Paz e Terra. Tradução de Marco Aurélio Nogueira [11. ${ }^{a}$ ed.].

Borón, Atilio (2003), Filosofia política marxista. São Paulo: Cortez.

Braga, Ruy (2014), "Precariado e sindicalismo no Brasil contemporâneo: um olhar a partir da indústria do call center", Revista Crítica de Ciências Sociais, 103, 25-52. DOI: $10.4000 /$ rccs. 5532 .

Brasil, Ministério da Saúde (2014), "Para entender o controle social na saúde”. Brasília: Ministério da Saúde, Conselho Nacional de Saúde.

Cohen, Joshua (2009), "Deliberação e legitimidade democrática", in Ângela Cristina Marques (org.), A deliberação pública e suas dimensões sociais, políticas e comunicativas. Belo Horizonte: Autêntica, 85-108.

CONASS - Conselho Nacional de Secretários de Saúde (2009), As conferências nacionais de saúde. Evolução e perspectivas. Brasília: CONASS.

Côrtes, Soraya Vargas (2009), "Conselhos e conferências de saúde: papel institucional e mudança nas relações entre Estado e sociedade”, in Sônia Fleury; Lenaura de Vasconcelos Costa Lobato (orgs.), Participação, democracia e saúde. Rio de Janeiro: Cebes, 102-128. 
Cunha, Eleonora (2007), "A efetividade deliberativa dos Conselhos Municipais de Saúde e de Criança e Adolescente no Nordeste”, in Leonardo Avritzer (org.), A participação social no Nordeste. Belo Horizonte: Editora da Universidade Federal de Minas Gerais, 135-162.

Dahl, Robert (2005), Poliarquia. Participação e oposição. São Paulo: Editora da Universidade de São Paulo. Tradução de Celso Mauro Paciornik.

Delgado, Mônica; Escorel, Sarah (2008), "Ensaio sobre a resolução 333/03 do CNS. Entre as dimensões política e técnica, e entre as dinâmicas participativa e fiscalizatória”, Divulgação em Saúde em Debate, 43, 79-95.

Dryzek, John (2004), "Legitimidade e economia na democracia deliberativa", in Vera Coelho; Marcos Nobre (orgs.), Participação e deliberação. Teoria democrática e experiências institucionais no Brasil contemporâneo. São Paulo: Editora 34, 41-62.

Escorel, Sarah (2012), "História das políticas de saúde no Brasil de 1964-1990”, in Lígia Giovanella; Sarah Escorel; Lenaura de Vasconcelos Costa Lobato; José Carvalho de Noronha; Antonio Ivo de Carvalho (orgs.), Políticas e sistema de saúde no Brasil. Rio de Janeiro: Fiocruz/Cebes, 323-364.

Escorel, Sarah; Delgado, Mônica (2008), "Perfil dos conselhos estaduais de saúde: singularidades e similaridades no controle social”, Divulgação em Saúde em Debate, 43, 62-78.

Faria, Cláudia Feres; Lins, Isabela (2013), "Participação e deliberação nas conferências de saúde: do local ao nacional”, in Leonardo Avritzer; Clovis Souza (orgs.), Conferências nacionais: atores, dinâmicas participativas e efetividades. Brasília: Ipea - Instituto de Pesquisa Econômica Aplicada.

Gerschman, Sílvia (2004), A democracia inconclusa: um estudo da reforma sanitária brasileira. Rio de Janeiro: Fiocruz [2. ${ }^{\text {a }}$ ed.].

Habermas, Jürgen (2002), A inclusão do outro. Estudos de teoria política. São Paulo: Edições Loyola. Tradução de George Sperber e Paulo Astor Soethe.

Labra, Maria Eliana (2009), "Política Nacional de Participação na Saúde: entre a utopia democrática do controle social e a práxis predatória do clientelismo empresarial”, in Sônia Fleury; Lenaura de Vasconcelos Costa Lobato (orgs.), Participação, democracia e saúde. Rio de Janeiro: Cebes, 176-203.

Lavalle, Adrian Gurza; Houtzager, Peter P.; Castello, Graziela (2006), "Democracia, pluralização da representação e sociedade civil”, Lua Nova - Revista de Cultura e Política, 67, 49-103.

Lobato, Lenaura (2009), "Prefácio”, in Sônia Fleury; Lenaura Lobato (orgs.), Participação, democracia e saúde. Rio de Janeiro: Cebes, 7-12.

Macinko, James; Harris, Matthew J. (2015), “Brazil's Family Health Strategy - Delivering Community-Based Primary Care in a Universal Health System”, The New England Journal of Medicine, 372(23), 2177-2181. 
Moreira, Marcelo Rasga (2016), "Reflexões sobre democracia deliberativa. Contribuições para os conselhos de saúde num contexto de crise política”, Saúde em Debate, 40(especial), 25-38.

Müller Neto, Júlio Strubing; Artmann, Elizabeth (2014), "Discursos sobre o papel e a representatividade de conferências municipais de saúde”, Cadernos de Saúde Pública, 30(1), 68-78.

Noronha, José Carvalho de; Lima, Luciana Dias de; Machado, Cristiani Vieira (2012), "O Sistema Único de Saúde - SUS”, in Lígia Giovanella; Sarah Escorel; Lenaura de Vasconcelos Costa Lobato; José Carvalho de Noronha; Antonio Ivo de Carvalho (orgs.), Políticas e sistema de saúde no Brasil. Rio de Janeiro: Fiocruz/ /Cebes, 365-394.

Oliveira, Lucia Conde; Pinheiro, Roseni (2010), "A participação nos conselhos de saúde e sua interface com a cultura política”, Ciência \& Saúde Coletiva, 15(5), 2455-2464.

Paim, Jairnilson; Travassos, Claudia; Almeida, Celia; Bahia, Ligia; Macinko, James (2011), "The Brazilian Health System: History, Advances, and Challenges", The Lancet, 377(9779), 1778-1797.

Paiva, Fernando Santana de; Stralen, Cornelis Johannes Van; Costa, Pedro Henrique Antunes da (2014), "Participação social e saúde no Brasil. Revisão sistemática sobre o tema”, Ciência \& Saúde Coletiva, 19(2), 487-498.

Pereira, Elisabete Oliveira; Côrtes, Soraya Vargas; Barcelos, Márcio (2009), "Conselho Estadual de Saúde do Rio Grande do Sul: histórico, funcionamento, atores e dinâmica das relações sociais”, in Soraya Vargas Côrtes (org.), Participação e saúde no Brasil. Rio de Janeiro: Fiocruz, 111-144.

Requena Mora, Marina; Rodríguez Victoriano, José Manuel (2017), “Más allá de la democracia representativa. La democracia real y los movimientos sociales en el Estado español”, Revista Crítica de Ciências Sociais, 113, 3-28. DOI: 10.4000/ rccs.6642.

Ricardi, Luciani Martins; Shimizu, Helena Eri; Santos, Leonor Maria Pacheco (2017), "As Conferências Nacionais de Saúde e o processo de planejamento do Ministério da Saúde", Saúde em Debate, 41(especial), 155-170.

Santos, Boaventura de Sousa; Avritzer, Leonardo (2005), "Introdução: para ampliar o cânone democrático”, in Boaventura de Sousa Santos (org.), Democratizar a democracia. Os caminhos da democracia participativa. Rio de Janeiro: Civilização Brasileira [3. ${ }^{a}$ ed.].

Schumpeter, Joseph (1976), Capitalism, Socialism \& Democracy. London: Taylor \& Francis [5. ${ }^{\mathrm{a}}$ ed.].

Serapioni, Mauro (2014), "Os desafios da participação e da cidadania nos sistemas de saúde", Ciência \& Saúde Coletiva, 19(12), 4829-4839. 
Silva, Marcelo Kunrath; Côrtes, Soraya Vargas; Réos, Janete Cardoso; Barcelos, Márcio (2009), "A dinâmica das relações sociais no Conselho Nacional de Saúde", in Soraya Vargas Côrtes (org.), Participação e saúde no Brasil. Rio de Janeiro: Fiocruz, 73-110. Vargas, Ingrid; Mogollón-Pérez, Amparo Susana; Unger, Jean-Pierre; Silva, Maria Rejane Ferreira da; Paepe, Pierre De; Vázquez, María Luisa (2015), "Regional-Based Integrated Healthcare Network Policy in Brazil. From Formulation to Practice", Health Policy and Planning, 30(6), 705-717.

Ventura, Carla Aparecida; Miwa, Marcela Jussara; Serapioni, Mauro; Jorge, Márjore

Serena (2017), "Cultura participativa: um processo de construção de cidadania no Brasil”, Interface - Comunicação, Saúde, Educação, 21(63), 907-920.

Artigo recebido a 01.02.2018

Aprovado para publicação a 05.07.2018

\author{
José Patrício Bispo Júnior \\ Instituto Multidisciplinar em Saúde, Universidade Federal da Bahia \\ Rua Hormindo Barros, 58, Bairro Candeias, CEP: 45.029-094, Vitória da Conquista - BA, Brasil \\ Contacto: jpatricio@ufba.br
}

\section{Advances and Challenges of Institutionalized Participation in Brazil's Health System}

This paper aims to analyze the main characteristics and challenges of institutionalized participation in the Brazil's health system. First, it discusses the features and principles of the Unified Health System (SUS), highlighting the importance of social mobilization in shaping the country's current health system. Next, the characteristics and attributes of health councils and conferences are presented as institutionalized mechanisms of participation. The health councils are analyzed for parity composition and deliberative function. Lastly, the results of the case study of the health council of the state of Bahia are discussed. The results demonstrated the

\section{Avancées et challenges de la participation institutionnalisée dans le cadre du système de santé du Brésil}

Le présent article a pour but de se pencher sur les principaux challenges et les principales caractéristiques induits par la participation institutionnalisée dans le cadre du système de santé brésilien. En premier lieu, nous abordons les caractéristiques et les principes du Système Unique de Santé, en soulignant l'importance de la mobilisation sociale dans la forme prise par l'actuel système de santé du pays. Ensuite, nous nous rapportons aux caractéristiques et aux attributions des conseils et conférences de santé en tant que mécanismes institutionnalisés de participation. Les conseils de santé sont étudiés en regard 
low power of the social representatives' agenda and the health council's fragile capacity to exert influence in the definition of health policy.

Keywords: Brazil; citizen participation; democracy; health systems. des caractéristiques de composition paritaire et de fonction délibérative. Enfin, nous nous penchons sur les résultats de l'étude du Conseil de Santé de l'état de Bahia, qui mettent en évidence que l'agenda des représentant sociaux est faible tout autant qu'est fragile la capacité d'influence du conseil sur la définition de la politique de santé.

Mots-clés: Brésil; démocratie; participation citoyenne; systèmes de santé. 